\title{
Monitoring pertumbuhan mangrove di area modulasi karang dan mangrove Kampus Tateli Politeknik Negeri Manado
}

\author{
(Monitoring mangrove growth in the coral and mangrove modulation area of the \\ Manado State Polytechnic Tateli Campus)
}

\author{
Dannie R.S.Oroh, Easter. Ch. M. Tulung dan Oktavianus Lintong \\ Program Studi Ekowisata Bawah Laut Jurusan Pariwisata Politeknik Negeri Manado
}

Corresponding author : dannieorohpolimdo@gmail.com

\begin{abstract}
Research conducted in the Coral and Mangrove Modulation Area of the Tateli Campus of the Polytechnic of Manado State, in January to October 2019 aims to identify and differentiate the types of mangroves and then obtain data on mangrove growth in the Coral \& Mangrove Modulation Area of the Tateli Campus. Retrieval of data using an area of $20 \mathrm{~m} 2$ of mangrove modulation and divided into four quadrants measuring $10 \mathrm{~m} 2$, while the tools used are: a compass to determine the direction or azimuth of research, a meter to measure distances., A photo camera for documentation tools, computers and other stationery which is used for data processing and writing research, rope, Tally sheet., Height measuring devices. Observations and data collection in this study included the measurement of trees, saplings, seedling height, seedling leaves, and seedling branches. From the existing mangrove modulation, four quadrants of mangrove observation were obtained. There are a number of mangrove individuals whose growth is observed and seen from the height, number of leaves and branches of the mangrove. Based on observations, it was found that in quadrant one there were two types of mangroves in the seedling phase, namely Rhizophora Apiculata and Rhizophora Mucronata with a total of 17 individuals. The average leaves of $R$. Apiculata are 7 strands. Then in the second quadrant two mangrove species were found, namely $R$. Apiculata and Sonneratia Alba, with a total of 15 individuals where the average height of Rhizophora Apiculata seedlings was $78 \mathrm{~cm}$, while Sonneratia Alba was $25.71 \mathrm{~cm}$. Furthermore, in this third quadrant only one species of mangrove Sonneratia Alba was found in the seedling phase. In this quadrant there are 15 mangrove individuals, with an average height value of $28.33 \mathrm{~cm}$, an average value of leaves of 7.8 strands, an average value of 0.27 branches and the last in the fourth quadrant there are four types of mangrove seedlings namely R. Apiculata, R. mucronata, Brugueira Gymnoriza, and Sonneratia Alba. In this quadrant, 30 individual mangrove seedlings were found. Based on these results it can be concluded that from the existing mangrove modulation, obtained four quadrants of mangrove observation. There are several mangrove individuals whose growth is observed, as seen from the height, number of leaves and branches of the mangrove. Then the average mangrove growth is dominated by $R$. mucronata species. Whereas the highest rate of mangrove growth for 10 months is Brugueira Sp.
\end{abstract}

Keywords: Mangroves, Growth

\section{ABSTRAK}

Penelitian yang dilaksanakan di Area Modulasi Karang dan Mangrove Kampus Tateli Politeknik Negeri Manado, pada bulan Januari sampai Oktober tahun 2019 ini berujuan untuk mengenal dan membedakan jenis - jenis mangrove kemudian mendapatkan data pertumbuhan mangrove yang berada di Area Modulasi Karang \& Mangrove Kampus Tateli. Pengambilan data dengan menggunakan luasan modulasi mangrove seluas $20 \mathrm{~m}^{2}$ dan dibagi menjadi empat kuadran berukuran $10 \mathrm{~m}^{2}$, sedangkan alat yang digunakan adalah: kompas untuk menentukan arah atau azimut penelitian, Meteran untuk mengukur jarak., Kamera foto untuk alat dokumentasi, Komputer dan alat tulis lainnya yang digunakan untuk pengolahan data dan penulisan penelitian, Tali, Tally sheet., Alat Pengukur tinggi. Pengamatan dan pengumpulan data dalam penelitian ini meliputi pengukuran pohon, pancang, tinggi semai, daun semai, dan cabang semai. Dari 
modulasi mangrove yang ada, di dapatkan empat kuadran pengamatan mangrove. Ada beberapa individu mangrove yang di amati pertumbuhannya dan yang dilihat dari tinggi, jumlah daun dan cabang mangrove. Berdasarkan pengamatan ditemukan bahwa pada kuadran satu didapatkan dua jenis mangrove dalam fase semai yaitu Rhizophora Apiculata dan Rhizophora Mucronata dengan jumlah total individu sebanyak sebanyak 17 individu. Rata-rata daun Rhizophora Apiculata 7 helai. Kemudian pada kuadran ke dua didapatkan dua jenis mangrove yaitu Rhizophora Apiculata dan Sonneratia Alba, dengan total individu sebanyak 15 individu dimana Rata-rata tinggi semai jenis Rhizophora Apiculata adalah $78 \mathrm{~cm}$, sedangkan Sonneratia Alba adalah $25.71 \mathrm{~cm}$. selanjutnya pada kuadran ke tiga ini hanya ditemukan satu jenis mangrove Sonneratia Alba fase semai. Pada kuadran ini terdapat 15 individu mangrove, dengan nilai ratarata tinggi $28,33 \mathrm{~cm}$, nilai rata-rata daun 7,8 helai, nilai rata-rata cabang 0,27 dan yang terakhir pada Pada kuadran ke empat didapatkan empat jenis mangrove fase semai yaitu Rhizophora Apiculata, Rhizophora mucronata, Brugueira Gymnoriza, dan Sonneratia Alba. Didalam kuadran ini didapatkan 30 individu mangrove fase semai. Berdasarkan hasil tersebut dapat disimpulkan bahwa dari modulasi mangrove yang ada, didapatkan empat kuadran pengamatan mangrove. Ada beberapa individu mangrove yang di amati pertumbuhannya, yang dilihat dari tinggi, jumlah daun dan cabang mangrove. Kemudian Rata-rata pertumbuhan mangrove didominasi oleh jenis Rhizophora mucronata. Sedangkan untuk laju pertumbuhan mangrove selang waktu 10 bulan yang paling tinggi adalah jenis Brugueira Sp.

Kata kunci: Mangrove, Pertumbuhan

Article History:

Received November, 152019

Accepted: November 20, 2019

Published: November 25, 2019 


\section{PENDAHULUAN}

\subsection{Latar Belakang}

Mangrove merupakan ekosistem dengan fungsi yang unik dalam lingkungan hidup. Oleh karena adanya pengaruh laut dan daratan, dikawasan mangrove terjadi interaksi kompleks antara sifat fisika dan sifat biologi. Karena sifat-fisiknya, mangrove mampu berperan sebagai penahan ombak serta penahan intrusi dan abrasi laut. Proses dekomposisi bakau atau mangrove yang terjadi mampu menunjang kehidupan makhluk hidup di dalamnya. Keunikan lainnya adalah fungsi serbaguna hutan mangrove sebagai penghasilan masyarakat desa di daerahpesisir, tempat berkembangnya biota laut tertentu dan flora-fauna pesisir, sertadapat juga dikembangkan sebagai wahana wisata untuk kepentingan pendidikandan observasi/penelitian.

Ekosistem hutan mangrove adalah suatu sistem ekologi yang terdiri dari komunitas vegetasi pantai tropis yang didominasi oleh beberapa jenis pohon mangrove yang mampu tumbuh dan berkembang pada daerah pasang surut pantai berlumpur.. Kerusakan ekosistem hutan mangrove adalah perubahan fisik biotik maupun abiotik didalam ekosistem hutan mangrove menjadi tidak utuh lagi atau rusak yang disebabkan oleh faktor alam dan faktor manusia. Pada umumnya kerusakan ekosistem hutan mangrove disebabkan oleh aktivitas manusia dalam penyalahgunaan sumberdaya alam di wilayah pantai tidak memperhatikan kelestarian, seperti : penebangan untuk keperluan kayu bakaryang berlebihan, tambak, permukiman, industri dan pertambangan. Kualitas lingkungan pesisir saat ini terus mengalami penurunan seiring dengan semakin meningkatnya jumlah penduduk di kawasan pesisir. Kenaikan jumlah penduduk di kawasan pesisir secara otomatis meningkatkan kebutuhan terhadap sandang, pangan, papan, air bersih dan energi, hal ini mengakibatkan eksploitasi terhadap sumber dayapesisir semakin meningkat. Dalam pengeksploitasiannya masyarakat cenderung mengabaikan aspek-aspek lingkungan dan bersifat merusak. Salah satu sumber daya pesisir yang saat ini mulai terancam adalah ekosistem mangrove yang mempunyai fungsi sebagai penyeimbang kawasan pesisir. Ekosistem mangrove sebagai salah satu ekosistem penting di kawasan pesisir, saat ini di seluruh dunia terus mengalami tekanan.

Luas mangrove dunia dalam F.A.O (2003) mencatat bahwa pada tahun 1980 mencapai 19,8 juta ha, turun menjadi 16,4 juta ha pada tahun 1990, dan menjadi 14,6 juta ha pada tahun 2000, sedangkan di Indonesia, luas mangrove mencapai 4,25 juta ha pada tahun 1980, turun menjadi 3,53 juta ha pada tahun 1990 dan tersisa 2,93 juta h pada tahun 2000. Mangrove 


\section{Jurnal Pesisir dan Laut Tropis}

mempunyai berbagai fungsi. Fungsi fisiknya yaitu untuk menjaga kondisi pantai agar tetap stabil, melindungi tebing pantai dan tebing 3 sungai, mencegah terjadinya abrasi dan intrusi air laut, serta sebagai perangkap zat pencemar. Fungsi biologis mangrove adalah sebagai habitat benih ikan, udang, dan kepiting untuk hidup dan mencari makan, sebagai sumber keanekaragaman biota akuatik dan nonakuatik seperti burung, ular, kera, kelelawar, dan tanaman anggrek, serta sumber plasma nutfah. Fungsi ekonomis mangrove yaitu sebagai sumber bahan bakar (kayu, arang), bahan bangunan (balok, papan), serta bahan tekstil, makanan, dan obat-obatan.

Hutan mangrove sebagai suatu ekosistem di daerah pasang surut, kehadirannya sangat berpengaruh terhadap ekosistem-ekosistem lain di daerah tersebut. Terjadinya kerusakan/gangguan pada ekosistem yang satu tentu saja akan mengganggu ekosistem yang lain. Sebaliknya keberhasilan dalam pengelolaan (rehabilitasi) hutan mangrove akan memungkinkan peningkatan penghasilan masyarakat pesisir khususnya para nelayan dan petani tambak karena kehadiran hutan mangrove ini merupakan salah satu faktor penentu pada kelimpahan ikan atau berbagai biota laut lainnya.

Menurut Gunarto (2004) mangrove dapat tumbuh subur di daerah muara sungai atau estuary yang merupakan daerah tujuan akhir dari partikel-partikel organik maupun endapan lumpur yang terbawa dari daerah

\section{Volume 7 Nomor 3 Tahun 2019}

hulu akibat adanya erosi. Kusmana (2007) mengemukakan bahwa hutan mangrove adalah suatu komunitas tumbuhan atau suatu individu jenis tumbuhan yang membentuk komunitas tersebut di daerah pasang surut. Menurut Bengen (1999) hutan mangrove merupakan komunitas vegetasi pantai tropis, yang didominasi oleh beberapa jenis pohon yang mampu tumbuh dan berkembang di daerah pasang surut pantai berlumpur.

Hutan mangrove, selain di kenal memiliki potensi ekonomi sebagai penyedia sumber daya kayu juga sebagai tempat pemijahan (spawning ground), daerah asuhan (nursery ground), dan juga sebagai daerah untuk mencari makan (feeding ground) bagi ikan dan biota laut lainnya, juga berfungsi untuk menahan gelombang laut dan intrusi air laut kearah darat (Suzana, et al, 2011). Fungsi lainnya adalah sebagai sumber penghasilan masyarakat pesisir yang dapat dikembangkan sebagai wisata, pertanian atau pertambakan, dan lain sebagainya.

Hutan mangrove sebagai suatu ekosistem di daerah pasang surut, kehadirannya sangat berpengaruh terhadap ekosistem lain di daerah tersebut. Terjadinya kerusakan pada ekosistem yang satu tentu saja akan mengganggu ekosistem yang lain. Sebaliknya keberhasilan dalam pengelolaan hutan mangrove akan memungkinkan peningkatan penghasilan masyarakat pesisir khususnya para nelayan dan petani tambak karena kehadiran hutan mangrove ini merupakan salah satu faktor penentu pada kelimpahan ikan atau berbagai biota laut lainnya (Sudarmadji, 2001). 


\section{Jurnal Pesisir dan Laut Tropis}

Politeknik Pariwisata Manado melakukan kegiatan penelitian mengenai laju pertumbuhan mangrove. Dengan menanam dan mencatat jenis dan pertumbuhan mangrove di sekitar wilayah kampus Tateli politeknik pariwisata Manado. Menurut Perdana (2008) faktor kesesuaian habitat penting bagi pertumbuhan hutan mangrove karena hutan ini sangat dipengaruhi oleh faktor-faktor yang berasal dari daratan dan lautan. Sebagai contoh faktor salinitas yang konsentrasinya sangat ditentukan oleh suplai air tawar dari daratan dan air asin yang berasal dari lautan. Hal ini yang menjadikan setiap kawasan memiliki tingkat keberhasilan yang berbeda-beda dalam melakukan penanaman mangrove jika ditinjau dari kondisi habitatnya.

\subsection{Tujuan}

1. Mengenal dan membedakan jenis jenis mangrove yang berada di Area Modulasi Karang \& Mangrove Kampus Tateli.

2. Mendapatkan data pertumbuhan mangrove diarea modulasi dan simulasinKarang dan Mangrove Kampus Tateli

\section{METODE PENELITIAN}

\subsection{Penelusuran Penelitian}

Hutan mangrove adalah hutan tumbuhan tingkat tiggi yang mampu beradaptasi diwilayah intertidal maupun diwilayah dengan tinggi permukaaan pasang surut rata-rata sampai pada

\section{Volume 7 Nomor 3 Tahun 2019}

wilayah dengan pasang tertinggi. Komunitas mangrove dapat tumbuh baik pada wilayah tropis dan mampu beradaptasi pada lingkungan yang ekstrim. Contoh seperti mempunyai sedimentasi yang tinggi, kondisi substrat tumbuh yang miskin oksigen atau tanpa oksigen, suhu dan salinitas tinggi, pasang surut yang ekstrim.

Adanya degradasi hutan mangrove di Indonesia dapat disebabkan oleh berbagai factor, yaitu adanya alih fungsi hutan mangrove menjadi kegiatan-kegiatan yang menunjang kegiatan pembangunan, seperti adanya pertumbuhan menjadi daerah permukiman, areal pertanian dan perkebunan, didirikannya bangunan dermaga serta aadanya kegiatan eksplorasi minyak dan gas bumi. Dengan adanya penurunan kualitas dan kuantitas hutan mangrove dapat mempengaruhi kehidupan ekonomi masayarakat pesisir, halini dapat dilihat adanya penurunan hasil tangkapan ikan yang berpengaruh langsung terhadap berkurangnya pendapatan nelayan. Dilain pihak hal ini juga dapat merusak keseimbangan ekosistem dan habitat serta kepunahan spesies ikan dan biota laut yang hidup didalamnya serta abrasi pantai. Degradasi mangrove semakin parah karena tidak ada ketegasan dalam penegakan hukum di Indonesia.

Secara keseluruhan kondisi kesehatan mangrove mempengaruhi kondisi lamun dan terumbu karang yang ada diwilayah pesisir. Dari segi fisik, adanya system perakaran mangrove yang 


\section{Jurnal Pesisir dan Laut Tropis}

khas memberikan perlindungan bagi lamn dan terumbu karang dari bahaya sedimentasi. Akar mangrove ini berfungsi menyaring materi berukuran besar yang terbawa oleh aliran sungai dan masuk ke laut. Upaya ini mencegah perairan menjadi keruh sehingga tidak terjadi penumpukkan dan penimbunan pada permukaan lamun dan karang. Secara ekologi, hutan mangrove merupakan suatu habitat bagi pertumbuhan biota-biota karang pada fase tertentu kehidupannya. Ketika eksistem mangroveterjaga, maka akan semakin banyak pilihan bagi masyarakat pesisir dalam memenuhi kebutuhan ekonomi disuatu area. Sebaliknya jika mangrove rusak, maka tekanan antropogenik akan semakin tinggi dirasakan oleh ekosistem terumbu karang. Karenanya diperlukan satu upaya pengelolaan yang mencakup usaha pemantauan ekologi terhadap kondisi komunitas mangrove pada suatu kawasan.

Kegiatan monitoring atau disebut juga pemantauan adalah kegiatan pengamatan atau pengukuran yang dilakukan pada rentang waktu tertentu secara berkelanjutan untuk mengetahui perkembangan dan perubahan dari objek yang diamati dari waktu ke waktu. Pada komunitas mangrove, monitoring atau pemantauan bertujuan untuk menghitung persentase tutpan mangrove dan kemudian mnentukan status kondisi hutan mangrove disuatu wilayah kajian.

Upaya rehabilitasi hutan mangrove dapat dilaksanakan baik pada kawasan yang telah dikuasai oleh masyarakat

\section{Volume 7 Nomor 3 Tahun 2019}

maupun pada kawasan yang tidak dikuasai oleh masyarakat dapat berjalan sesuai yang diinginkan, hal tersebut dapat didukung dengan melibatkan unsur masyarakat sekitar kawasan pesisir dan instansi pemerintah terkait.

Riset tentang strategi konservasi mangrove perlu dilakukan dengan konsep konservasi mangrove berbasis TRM yang bertujuan untuk (1) mengetahui INP (Indeks Nilai Penting) mangrove di zonasi A 50 meter dari pantai, zonasi B 50 meter dari sungai, dan zonasi C 50 meter dari darat, (2) melakukan pendekatan kepada masyarakat sekitar terkait partisipasi dalam konservasi mangrove, (3) membuat strategi konservasi hutan mangrove berbasis Tanam, Rawat dan Monitoring.

Dengan adanya masalah yang mengancam dikawasan ekosistem mangrove mendorong utnuk mengadakan penelitian tentang pertumbuhan mangrove di area modulasi dan simulasi karang dan mangrove Kampus Tateli Politeknik Negeri Manado. Hal ini sebagai salah satu upaya untuk melakukan pemulihan dan rehabilitasi dikawasan mangrove yang berpengaruh postif terhadap ekologi dan ekonomi manusia

\subsection{Bahan dan Metode}

\subsubsection{Lokasi dan Waktu Pelaksanaan}

Penelitian dilakukan di lokasi Kampus B Politeknik Negeri Manado, Jurusan Pariwisata di Desa Tateli Kabupaten Minahasa tepatnya pada Wilayah Modulasi Penanaman Mangrove. Waktu penelitian 
Jurnal Pesisir dan Laut Tropis

dilakukan pada tanggal Januari - Oktober 2019.

\section{Volume 7 Nomor 3 Tahun 2019}

Penelitian dilakukan di Politeknik Pariwisata Manado, tepatnya pada wilayah modulasi penanaman mangrove. (gambar 1)

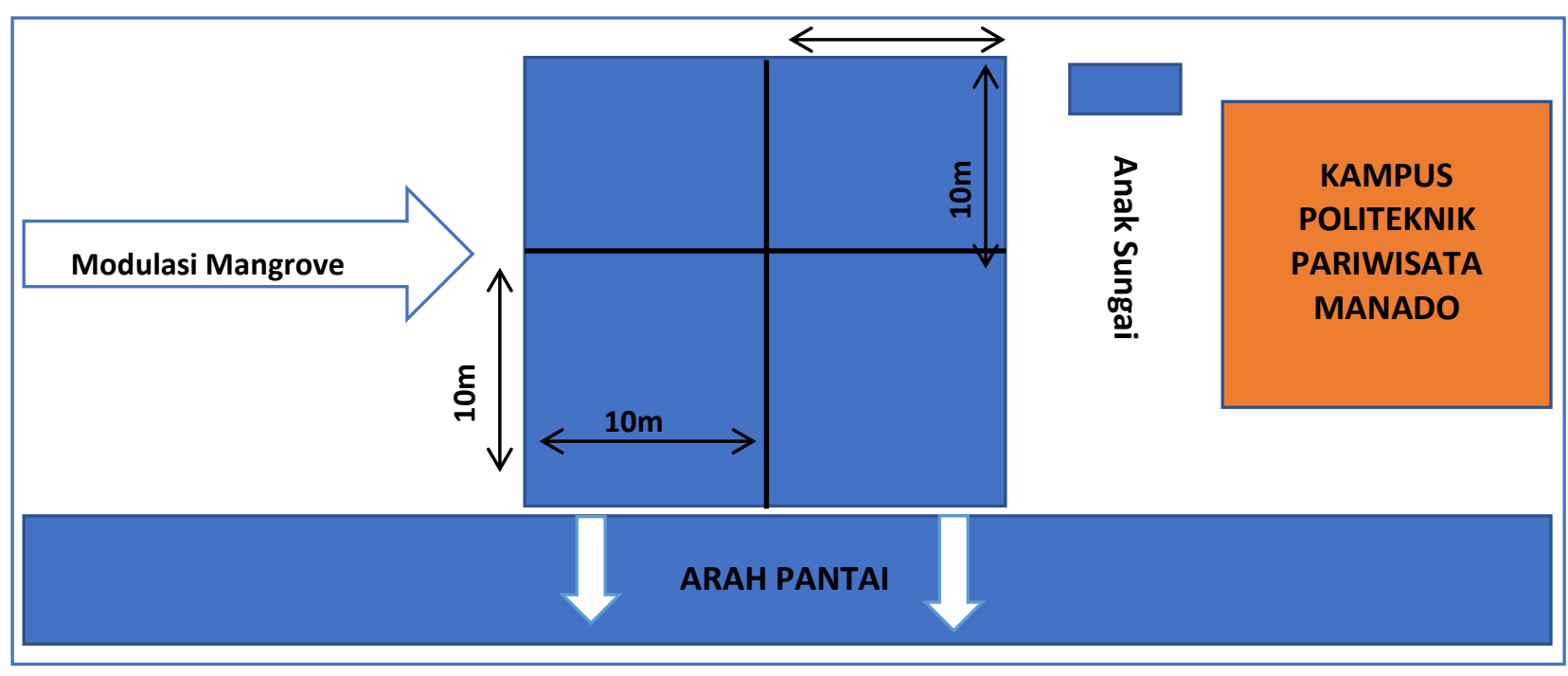

Gambar 1. Lokasi Penelitian Modulasi Mangrove

\subsubsection{Bahan dan Alat}

Bahan yang digunakan luasan modulasi seluas $20 \mathrm{~m}^{2}$, yang di bagi menjadi 4 kuadran berukuran $10 \mathrm{~m}^{2}$. Alat yang digunakan adalah: kompas untuk menentukan arah atau azimut penelitian, Meteran untuk mengukur jarak., Kamera foto untuk alat dokumentasi, Komputer dan alat tulis lainnya yang digunakan untuk pengolahan data dan penulisan penelitian, Tali, Tally sheet dan Alat Pengukur tinggi.

\subsubsection{Metode Penelitian}

Pengamatan dan pengumpulan data dalam penelitian ini meliputi pengukuran pohon, pancang, tinggi semai, daun semai, dan cabang semai.

Pengamatan dan pengumpulan data dalam penelitian ini meliputi pengukuran pohon, pancang, tinggi semai, daun semai, dan cabang semai. Obyek dalam penelitian ini adalah pelestarian mangrove dalam bentuk modulasi diarea simulasi mangrove dan karang. Pelestarian yang dimaksud disini adalah penanaman kembali atau reboisasi diarea tertentu yang ada didarat untuk selanjutnya setelah bertumbuh dengan baik maka akan dipindahkan atau dikembalikan pada substrat aslinya, yaitu daerah aslinya yang berlumpur, yang selalu tergenang air karena pengaruh pasang surut yang terjadi di wilayah pesisir.

\section{Data dan Sumber Data}

\section{- Data Primer}

Data primer diperoleh dari monitoring dan observasi lapangan dan wawancara secara langsung untuk memperoleh data perkembangan dan pengelolan hutan mangrove yang berada di Desa Tatell 


\section{Jurnal Pesisir dan Laut Tropis}

kecamatan Pineleng. Data primer yang dikumpulkan meliputi: a) Perubahan garis pantai. b) Perkembangan hutan mangrove. c) Degradasi hutan mangrove.

Adanya kegiatan Wawancara untuk memperoleh data primer dan data sekunder juga dilakukan kepada pemerintah dan masyarakat terkait rehabilitasi hutan mangrove dan manfaat ekonomi hutan mangrove. Wawancara kepada masyarakat ini dilakukan untuk memperoleh informasi mengenai kondisi aktual hutan mangrove pra dan pasca rehabilitasi dan reboisasi mangrove.

\section{- Data Sekunder}

Data sekunder adalah data yang telah lebih dulu dikumpulkan dan dilaporkan oleh orang atau instansi diluar diri penelitian diri, walaupun data yang dikumpulkan itu sebenarnya data yang asli. Dalam penelitian ini data sekunder yang diperlukan antara lain: a) data kondisi geografis lokasi penelitian Data jumlah penduduk desa lokasi penelitian b) Data kondisi hutan mangrove (berasal dari Dinas Kelautan dan Perikanan, Lingkungan Hidup, dan Dinas Pertanian)

\section{Prosedur Pelaksanaan Penelitian}

Beberapa faktor lingkungan penting yang harus diperhatikan sebelum melakukan tahap penanaman mangrove antara lain adalah tipe substrat, salinitas, temperature, ketinggian tanah, $\mathrm{pH}$, musim dan saluran air. Substrat untuk penanaman mangrove harus sesuai dengan jenis mangrove yang akan ditanam. Secara sederhana, pada sedimen

\section{Volume 7 Nomor 3 Tahun 2019}

yang berlumpur, sebagai contoh pada jenis Rhizopora spp adalah jenis mangrove yang tepat untuk ditanam. Avicennia spp dan Sonneratia spp, menyukai tanah berpasir yang berada di pinggiran pantai. Jenis mangrove lainnya seperti Ceriops spp dan Bruguiera spp bisa hidup bervariasi di substrat lumpur berpasir. Salinitas atau kadar garam juga perlu diperhatikan, karena mangrove hidup pada salinitas yang bervariasi. Kadar salinitas yang bervariasi ini ikut pula menentukan pola penyebaran mangrove di habitatnya.

Penentuan jenis mangrove untuk ditanam disuatu lokasi harus disesuaikan dengan kondisi substratnya dan budaya masyarakat lokal setempat. Beberapa hal yang ditemui dilapangan menginformasikan bahwa jenis - jenis mangrove tertentu cenderung "tidak" disukai untuk ditanam di daerah tertentu, sebagai contoh di Surodadi, misalnya jenis mangrove Rhizopora spp cenderung tidak bnyak ditanam tetapi ditebangi, karena di wilayah tersebut perakaran Rhizopora spp ditengarai telah menyebabkan jebolnya tanggul pertambakan mereka. Untuk itu, mangrove jenis Avicennia spp yang dianggap memiliki sistem perakaran yang lebih rapat dan dapat menstabilkan tanah tambak dan sekitar wilayah pesisir. Prosedur yang dilakukan dalam penelitian ini mencakup 2 hal yaitu : 1) Prosedur Penananam Mangrove dan 2) Prosedur Pemeliharaan Kawasan Mangrove.

\section{1) Prosedur Penanaman Mangrove}

Secara teori penanaman mangrove dengan mempergunakan bibit mangrove akan memiliki tingkat keberlangsungan dalam hidup 


\section{Jurnal Pesisir dan Laut Tropis}

atau proses adaptasi yang lebih tinggi apabila dibandingkan dengan penanaman mangrove dengan menggunakan propagul. Namun demikian, penanaman mangrove dengan propagul tanpa penyemaian sebaiknya juga dilakukan terutama pada saat penyulaman. Faktanya, penanaman mangrove menggunakan propagul juga seringkali dilakukan dengan alasan bibit mangrove lebih mudah menyesuaikan diri terhadap lingkungan. Sementara itu, penggunaan propagul sebagai "bahan baku" penanaman mangrove, walaupun diklaim memiliki daya adaptasi yang lebih tinggi, tetapi tidak demikian dengan daya tahannya terhadap gelombang.

Selanjutnya, penanaman bibit mangrove harus dikelompokkan sesuai dengan jenisnya. Hal ini dilakukan mengingat pada kondisi alami, mangrove memamng membentuk tegakan murni yang berarti ditemukan secara berkelompok sesuai dengan jenisnya. Penanaman mangrove sebaiknya dilakukan pada saat air laut surut. Namun demikian, apabila keadaan tidak memungkinkan, maka penanaman mangrove bisa tetap dilaksanakan pada saat air tergenang dengan syarat pada saat melakukan penanaman akar bibit benar benar tertancap dengan baik di sedimen dan terikat kuat di smaping ajirnya. Alat dan bahan yang dipergunakan untuk melakukan tahapan penanaman mangrove adalah bibit mangrove berbagai jenis, cetok, ajir dan tali rafia.

Teknik penanamannya sendiri adalah sebagai berikut:

- Penyediaan lahan atau bedeng bersama dengan substratnya. Lahan

\section{Volume 7 Nomor 3 Tahun 2019}

atau bedeng yang disiapkan berukuran $8 \times 3 \mathrm{~m}$ berada pada 3 tempat.

- Ambil satu bibit mangrove di area wilayah peisisir Desa Tateli dengan semua sedimen dan akar bibit yang ada.

- Tanam langsung bibit mangrove ke lahan atau bedeng yang telah disiapkan dengan cara melubangi tanah dengan cetok, sedemikian rupa hingga lubang penanaman cukup dalam, sehingga akar bisa tertanam dengan baik.

- Timbun dengan tanah. Jangan terlalu menekan tanah, sehingga oksigen bisa dengan leluasa keluar masuk ke dalam tanah.

Tidak semua bibit mangrove harus ditanam pada saat penanaman, melainkan bisa disisihkan untuk tahapan selanjutnya, yaitu penyulaman. Penyulaman adalah tahapan penting setelah tahapan penanaman, /yang bertujuan untuk memelihara bibit - bibit mangrove yang telah ditanam agar mendapatkan kelulushidupannya yang maksimal. Penyulaman dilakukan dengan cara mengganti bibit - bibit mangrove yang telah mati dengan bibit - bibit mangrove yang baru. Sebagai contoh, dari 100 bibit yang ada, bisa disisihkan 20 bibit untuk digunakan dalam kegiatan atau proses penyulaman. (gambar 2) 
Jurnal Pesisir dan Laut Tropis

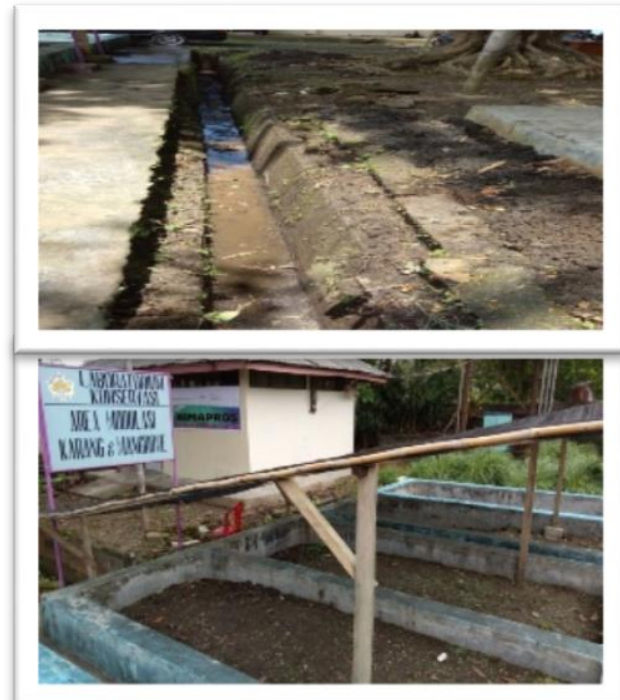

Volume 7 Nomor 3 Tahun 2019

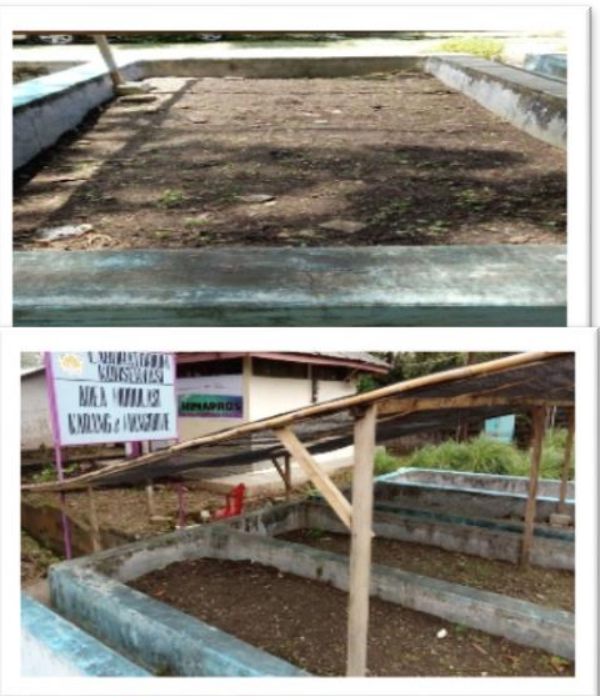

Gambar 2. Prosedur Penanaman Mangrove

Hal ini penting untuk memaksimalkan

\section{Pemeliharaan Kawasan Mangrove}

Tahap ini adalah tahap lanjutan setelah tahap penyulaman selesai dilakukan. Tahapan pemeliharaan mangrove memiliki tujuan jangka panjang untuk memastikan agar bibit - bibit mangrove, bisa hidup dalam jangka waktu yang lama. Hal yang harus dilakukan pada tahapan ini adalah program penjarangan, berupa penebangan beberapa buah dan batang pohon mangrove muda, Jika ditenggarai bibit mangrove yang berhasil tumbuh memiliki kepadatan yang sangat tinggi. pertumbuhan pohon mangrove lainnya.

Selain itu kestersediaan air yang banyak yang membantu pertumbuhan mangrove sehingga pertumbuhannya secara optimal. Selain penjarangan, dilakukan juga pembersihan lokasi terhadap hama dan gangguan lain seperti rumput liar, adanya pencemaran minyak dan gangguan lainnya, serta pengelolaan saluran air. (gambar 3)

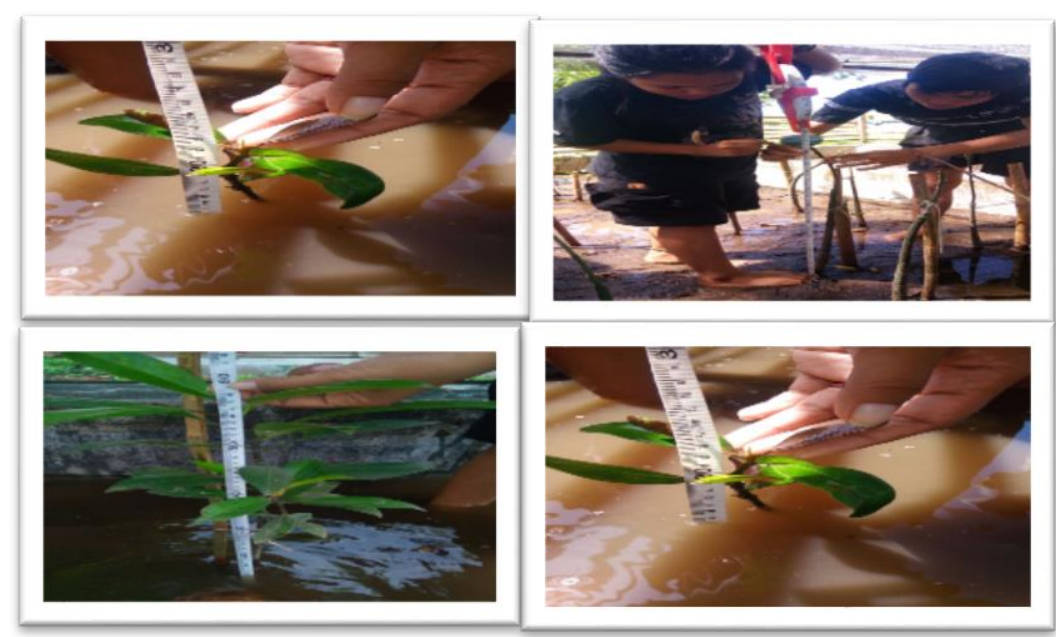

Gambar 3. Pemeliharaan Kawasan Mangrove 


\section{Jurnal Pesisir dan Laut Tropis}

\section{Mangrove ke Substrat Asalnya}

Mangrove yang telah melalui pertumbuhan yang optimal pada bedeng atau lahan diarea modulasi dan simulasi karang dan mangrove selanjutnya dipindahkan ke substrat asalnya. Dengana melalui langkah-langkah sebagai berikut.:

- Ambil satu bibit mangrove dari area modulasi dan simulasi karang dan mangrove bersama semua sedimen dan akar yang ada.

- Tanam langsung mangrove yang sudah baik pertumbuhannya ke substrat asalnya yaitu substrat yang berlumpur yang telah disiapkan dengan cara melubangi tanah dengan cetok, sedemikian rupa hingga lubang

\section{HASIL DAN PEMBAHASAN}

Dari modulasi mangrove yang ada, di dapatkan empat kuadran pengamatan mangrove. Ada beberapa individu mangrove yang di amati pertumbuhannya, yang dilihat dari tinggi, jumlah daun dan cabang mangrove. Dari pengamatan yang sudah dilakukan didapatkan hasil sebagai berikut:

\section{Volume 7 Nomor 3 Tahun 2019}

penanaman cukup dalam, sehingga akar bisa tertanam dengan baik.

- Timbun dengan tanah. Jangan terlalu menekan tanah, sehingga oksigen bisa dengan leluasa keluar masuk ke dalam tanah.

- Ambil poly bag yang terletak diatas ajr, kumo=pulkan menjadi satu disebuah keranjang atau plastic. Selanjutnya polybag dapat didaur ulang menjadi berbagai macam barang plastic daur ulang.

Sama seperti proses penanaman pada bedeng maka dilakukan juga proses penyulaman, dengan mengganti bibit - bibit mangrove yang telah mati dengan bibit bibit mangrove yang baru. Sebagai contoh, dari 100 bibit yang ada, bisa disisihkan 20 bibit untuk digunakan dalam kegiatan atau proses penyulaman.

\subsection{Kuadran Satu}

Pada kuadran satu didapatkan dua jenis mangrove dalam fase semai yaitu Rhizophora Apiculata dan Rhizophora Mucronata dengan jumlah total individu sebanyak sebanyak 17 individu. Pada kuadran satu ini tinggi rata-rata dari Rhizophora Apiculata adalah 60,21cm sedangkan Rhizophora Apiculata adalah $67,67 \mathrm{~cm}$, rata-rata jumlah daun Rhizophora Apiculata adalah sebanyak 12 helai sedangkan Rhizophora Mucronata 7 helai. (gambar 4) 


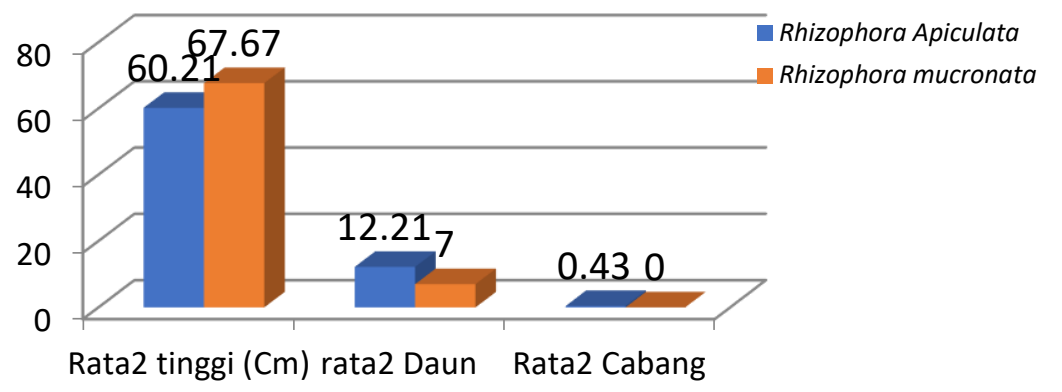

Gambar 4. Rata-rata Pertumbuhan Mangrove Pada Kuadran 1

\subsection{Kuadran Dua}

Pada kuadran ke dua ini didapatkan dua jenis mangrove yaitu Rhizophora Apiculata dan Sonneratia Alba, dengan total individu sebanyak
15 individu. Rata-rata tinggi semai jenis Rhizophora Apiculata adalah $78 \mathrm{~cm}$, sedangkan Sonneratia Alba adalah $25.71 \mathrm{~cm}$. Rata-rata daun Rhizophora Apiculata 7 helai. (gambar 5)

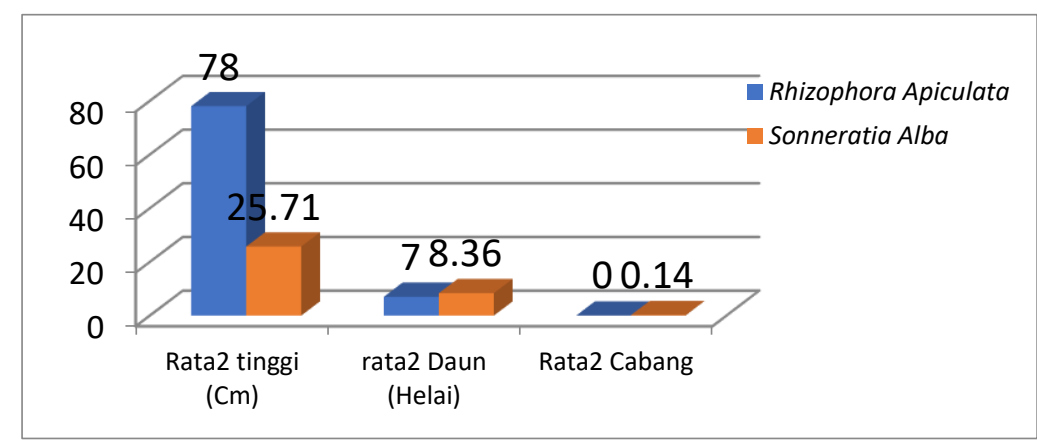

Gambar 5. Rata-rata Pertumbuhan Mangrove Pada Kuadran 2

\subsection{Kuadran ke Tiga}

Pada kuadran ke tiga ini hanya ditemukan satu jenis mangrove Sonneratia Alba fase semai. Pada kuadran ini terdapat
15 individu mangrove, dengan nilai rata-rata tinggi $28,33 \mathrm{~cm}$, nilai rata-rata daun 7,8 helai, nilai rata-rata cabang 0,27 . (gambar 6 )

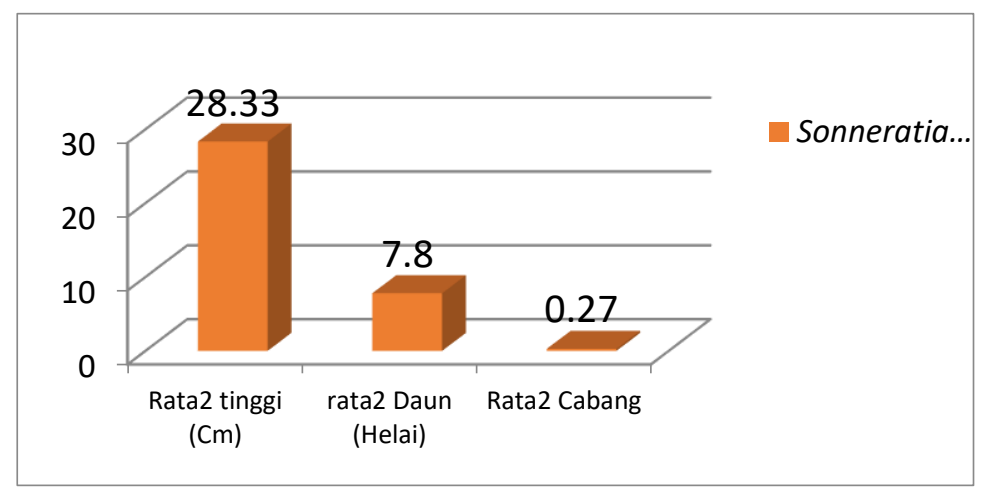

Gambar 6. Rata-rata Pertumbuhan Mangrove Pada Kuadran 3 


\section{Jurnal Pesisir dan Laut Tropis}

\subsection{Kuadran ke empat}

Pada kuadran ke empat didapatkan empat jenis mangrove fase semai yaitu Didalam kuadran ini didapatkan 30 individu mangrove fase semai. Rata-rata tinggi jenis mangrove pada kuadran ini adalah $57,38 \mathrm{~cm}$ untuk Rhizophora Apiculata, 60,83cm untuk Brugueira Gymnoriza, 29,33cm untuk Sonneratia Alba, dan $73,25 \mathrm{~cm}$ untuk Rhizophora mucronata. Sedangkan untuk nilai

\section{Volume 7 Nomor 3 Tahun 2019}

Rhizophora Apiculata, Rhizophora mucronata, Brugueira Gymnoriza, dan Sonneratia Alba.

rata-rata duan mangrove adalah sebagai berikut, 12,63 helai untuk Rhizophora Apiculata, 26,83 helai untuk Brugueira Gymnoriza, 5,83 helai untuk Sonneratia Alba, dan 10,25 untuk $R$ hizophora mucronata.

(gambar 7)

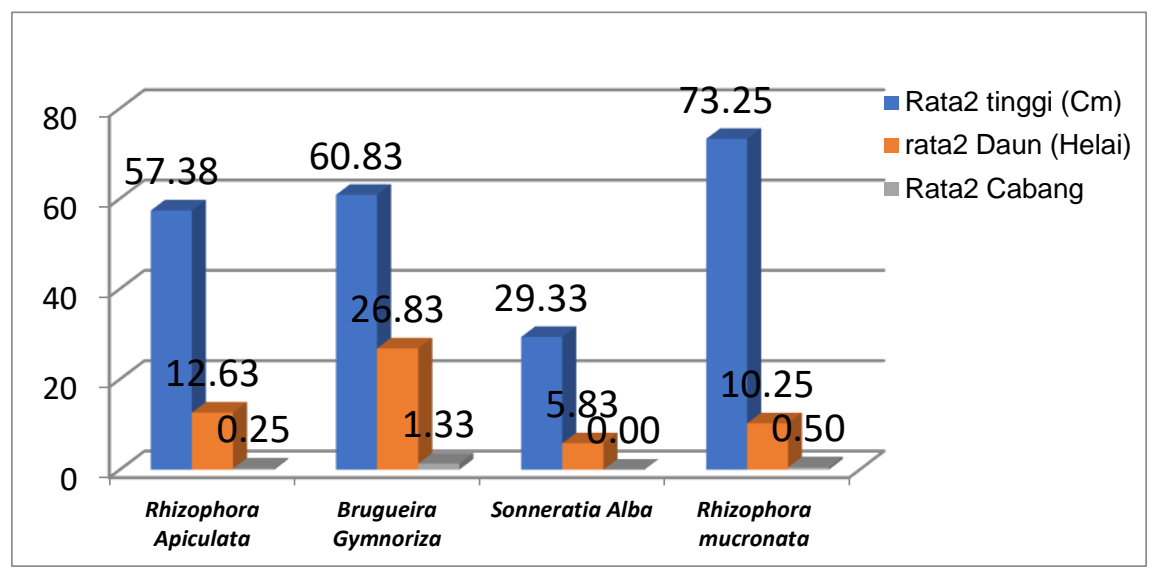

Gambar 7. Rata-rata Pertumbuhan Mangrove Pada Kuadran 4

\section{5. Laju Pertumbuhan Mangrove}

\subsubsection{Laju Pertumbuhan Mangrove jenis}

Rhizophora Sp

Bila data tinggi rata-rata mangrove jenis Rhizophora Sp pada tahun 2018 yang sebesar $54 \mathrm{~cm}$ dibandingkan dengan data tinggi rata-rata mangrove Rhizophora $S p$ tahun 2019 sebesar $63 \mathrm{~cm}$, terjadi kenaikan pertumbuhan pada tinggi semai sebanyak
$9 \mathrm{~cm}$. Sedangkan bila dilihat pertumbuhan rata-rata daun mangrove jenis Rhizophora $S p$ pada tahun 2018 yang sebanyak 6 helai daun dibandingkan dengan rata-rata daun mangrove jenis Rhizophora $S p$ pada tahun 2019 yang sebanyak 11 helai menandakan terjadi pertumbuhan daun rata-rata sebanyak 5 helai dalam kurun waktu 10 bulan. (gambar 8) 


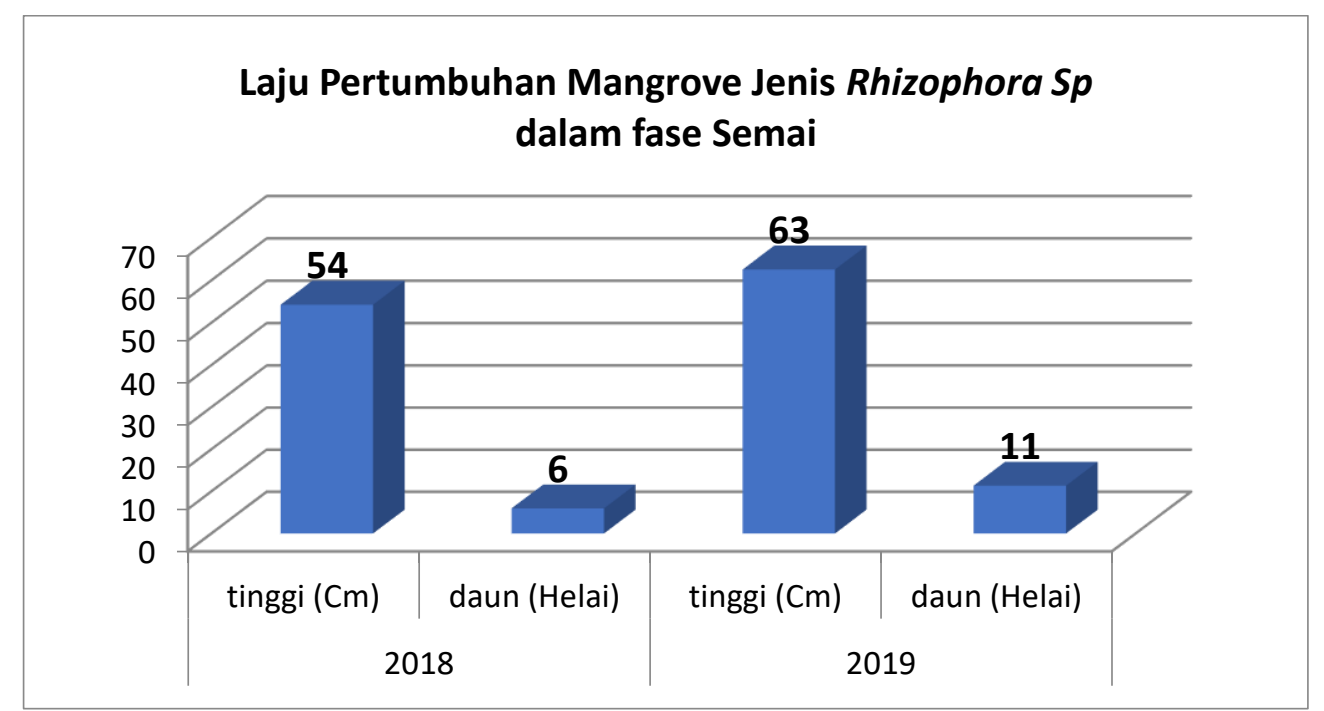

Gambar 8. Laju Pertumbuhan tinggi dan daun Mangrove jenis Rhizophora Sp

3.5.2. Laju Pertumbuhan Mangrove Jenis Sonneratia Sp.

Bila data tinggi rata-rata mangrove jenis Sonneratia Sp pada tahun 2018 yang sebesar $24 \mathrm{~cm}$ dibandingkan dengan data tinggi rata-rata mangrove jenis Sonneratia $S p$ tahun 2019 sebesar 27cm, terjadi kenaikan pertumbuhan pada tinggi semai rata-rata sebanyak $3 \mathrm{~cm}$. Sedangkan bila dilihat pertumbuhan rata-rata daun mangrove jenis Sonneratia Sp pada tahun 2018 yang sebanyak 7 helai daun dibandingkan dengan rata-rata daun mangrove jenis Sonneratia $S p$ pada tahun 2019 yang sebanyak 8 helai menandakan terjadi pertumbuhan daun ratarata sebanyak 1 helai dalam kurun waktu 10 bulan. (gambar 9)

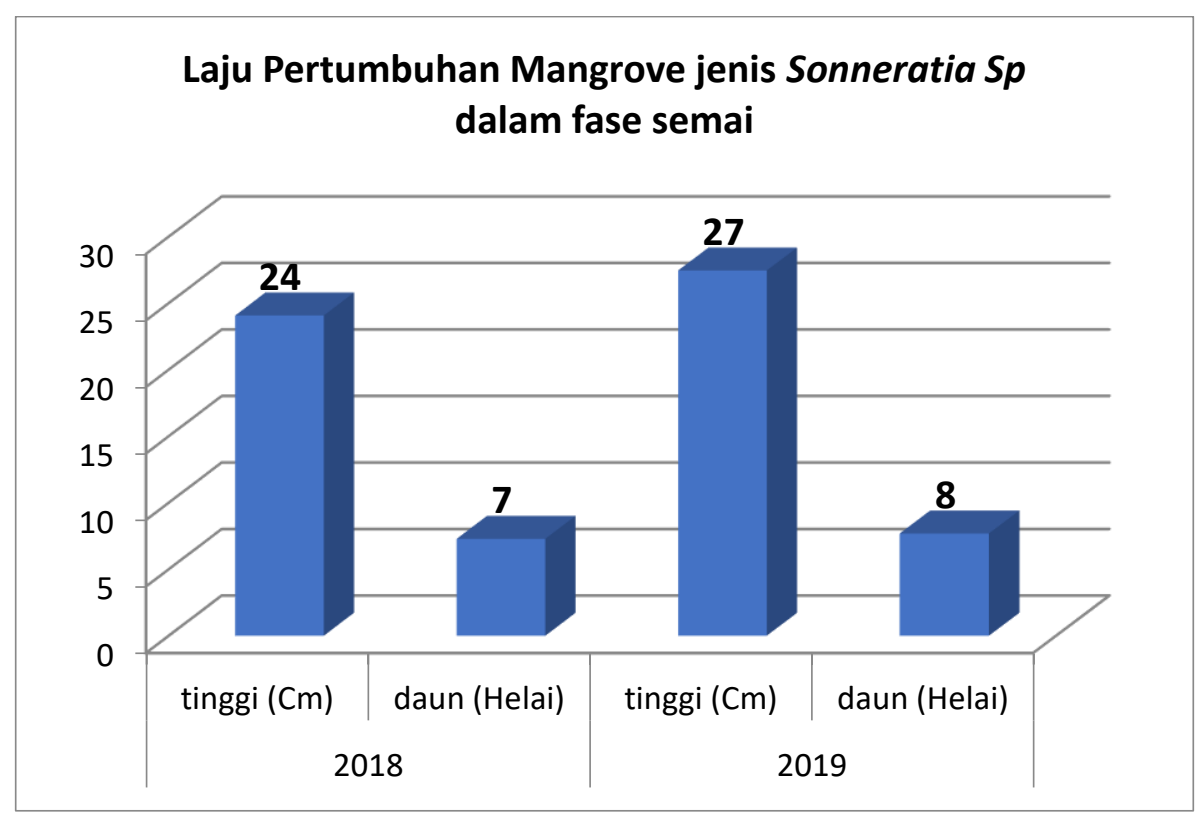

Gambar 9. Laju Pertumbuhan tinggi dan daun Mangrove jenis Sonneratia $S p$ 
3.5.3. Laju Pertumbuhan Mangrove Jenis Brugueira Sp

Bila data tinggi rata-rata mangrove jenis Brugueira Sp pada tahun 2018 yang sebesar $56 \mathrm{~cm}$ dibandingkan dengan data tinggi rata-rata mangrove jenis Brugueira $S p$ tahun 2019 sebesar $68 \mathrm{~cm}$, terjadi kenaikan pertumbuhan pada tinggi semai rata-rata sebanyak $12 \mathrm{~cm}$. Sedangkan bila dilihat pertumbuhan rata-rata daun mangrove jenis Brugueira Sp pada tahun 2018 yang sebanyak 13 helai daun dibandingkan dengan rata-rata daun mangrove jenis Brugueira Sp pada tahun 2019 yang sebanyak 27 helai menandakan terjadi pertumbuhan daun rata-rata sebanyak 14 helai dalam kurun waktu 10 bulan.

(gambar 10)

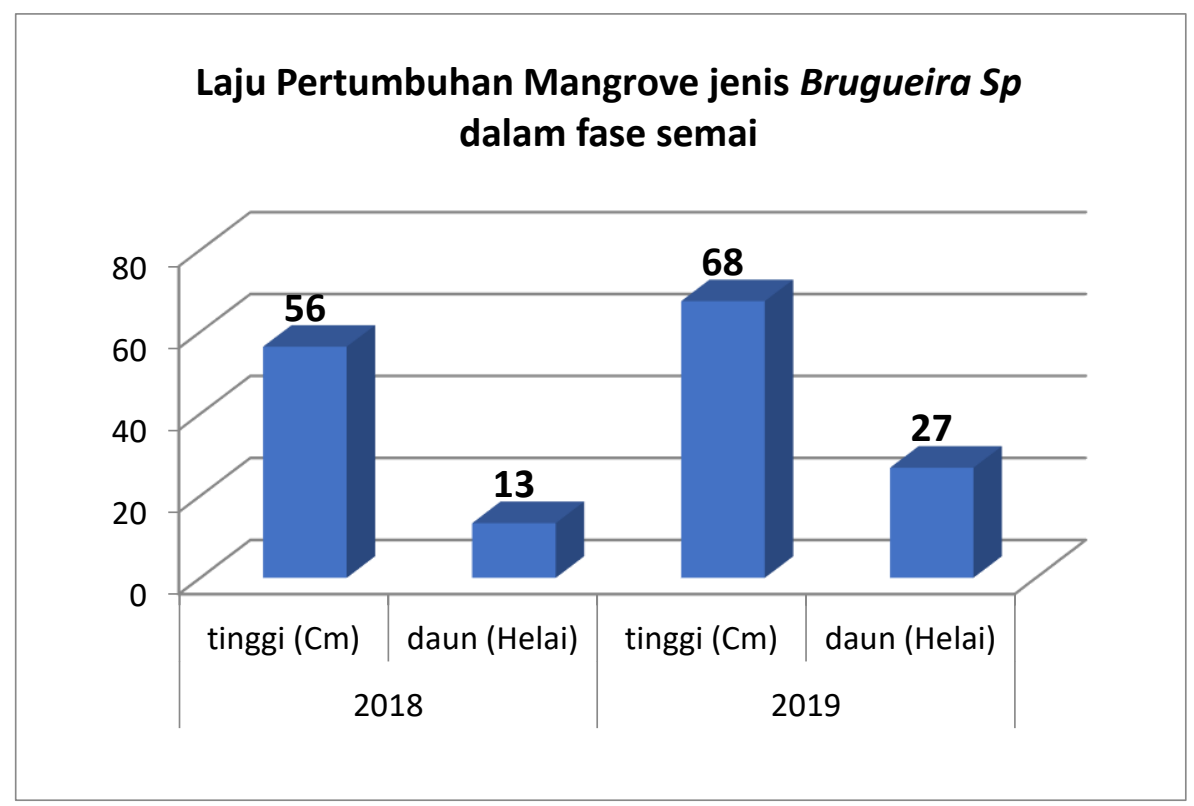

Gambar 10. Laju Pertumbuhan tinggi dan daun Mangrove jenis Brugueira Sp

3.6. Perbandingan laju pertumbuhan tinggi dan daun jenis mangrove Rhizophora $S p$, Sonneratia Sp dan Brugueira Sp

Dari data yang didapatkan laju pertumbuhan tinggi dan daun ketiga jenis mangrove ini, memiliki perbedaan laju pertumbuhan. Laju pertumbuhan tinggi dan daun mangrove dalam selang waktu sepuluh (10) bulan yang termasuk cepat adalah mangrove jenis Brugueira Sp, dimana dalam selang waktu 10 bulan pertumbuhan tinggi dan daun sebanyak $12 \mathrm{~cm}$ dan 14 helai. Jadi rata-rata pertumbuhan perbulan adalah tinggi $1,2 \mathrm{~cm}$ dan 1,4 helai daun. Laju pertumbuhan Kedua adalah jenis Rhizophora Sp karena dalam selang waktu 10 bulan terjadi pertumbuhan sebesar $9 \mathrm{~cm}$ untuk tinggi dan 5 helai untuk daun, jika dibagi 10 bulan bisa disimpulkan pertumbuhan mangrove jenis Rhizophora $S p$ sebesar $0,9 \mathrm{~cm}$ perbulan dan 0,5 helai perbulan. Laju pertumbuhan terakhir adalah jenis Sonneratia $S p$, karena dalam selang waktu 10 bulan, pertumbuhan tinggi dan daun mangrovenya hanya sebesar $3 \mathrm{~cm}$ untuk tinggi dan 1 helai (gambar 11) 


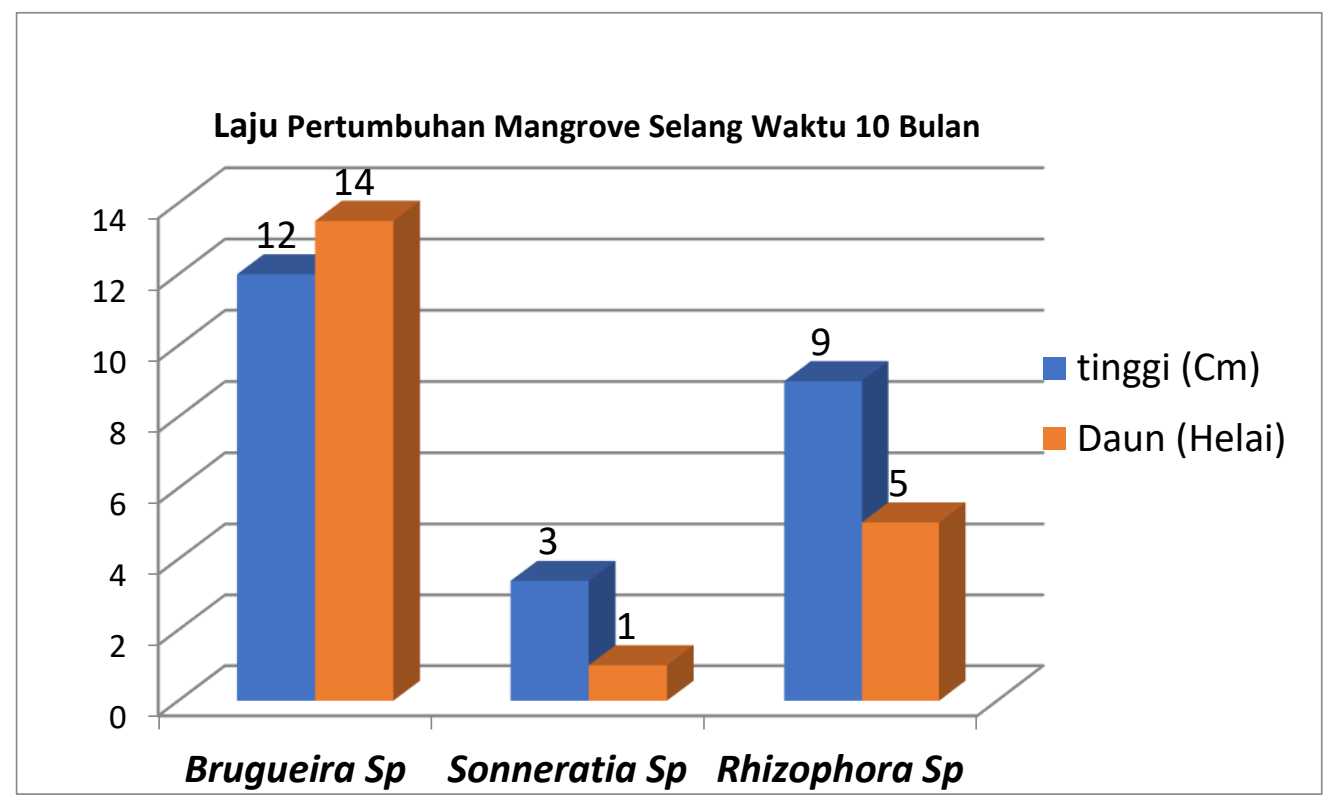

Gambar 11. Perbandingan laju pertumbuhan jenis mangrove Rhizophora Sp, Sonneratia Sp dan Brugueira Sp

\section{Kesimpulan}

\section{KESIMPULAN}

1. Dari modulasi mangrove yang ada, di dapatkan empat kuadran pengamatan mangrove. Ada beberapa individu mangrove yang di amati pertumbuhannya, yang dilihat dari tinggi, jumlah daun dan cabang mangrove

2. Rata-rata pertumbuhan mangrove didominasi oleh jenis Rhizophora mucronata

3. Laju pertumbuhan mangrove selang waktu 10 bulan yang paling tinggi adalah jenis Brugueira Sp

\section{DAFTAR PUSTAKA}

Bengen, D. G. 2001. Pengenalan dan Pengelolaan Ekosistem Mangrove. Pusat Kajian Sumberdaya Pesisir dan Lautan. IPB. Bogor.
Soerianegara, I. dan A. Indrawan. 1985. Ekologi Hutan Indonesia. Departemen Manajemen Hutan Fakultas Kehutanan IPB. Bogor.

Supriharyono. 2000. Pelestarian dan Pengelolaan Sumberdaya Alam di Wilayah Pesisir Tropis. PT. Gramedia Pustaka Utama. Jakarta.

Suryati, D.A. 1991. Studi Komunitas Burung dan Vegetasi di Kawasan Hutan Kota Kemayoran, Jakarta. Skripsi Sarjana Fakultas Biologi Universitas Nasional Jakarta. Tidak diterbitkan.

Suwelo, I.S. 1993. Jenis - Jenis Burung di Jakarta Ditinjau dari Segi Ekologi. Makalah Seminar Sehari "Burung dan Upaya Pelestariannya", KPB Symbiose FMIPA Biologi UI. Jakarta. 